\title{
A review of central nervous system leukaemia in paediatric acute myeloid leukaemia
}

\author{
Donna L. Johnston \\ Division of Hematology/Oncology, Children's Hospital of Eastern Ontario, Ottawa, Ontario, Canada. \\ Correspondence: Donna Johnston. Address: Children's Hospital of Eastern Ontario 401 Smyth Road Ottawa, Ontario \\ K1H 8L1 Canada. Telephone: 1-613-7377-600 ext. 2370. Fax: 1-613-738-4828. E-mail: djohnston@cheo.on.ca
}

Received: October 8, 2011

Accepted: November 21, 2011

Published: December 1, 2011

DOI : $10.5430 /$ jhm.v1n1p1

URL: http://dx.doi.org/10.5430/jhm.v1n1p1

The treatment of pediatric acute myeloid leukemia (AML) is the subject of many studies by collaborative groups around the world. These studies have examined both variations in the timing of chemotherapy agents being given, as well as the addition or omission of specific chemotherapeutic agents. In cooperative group studies, the methods utilized for the treatment of central nervous system (CNS) leukemia have remained relatively stable over the years. However, there are significant differences among the different cooperative groups as to the therapy used to treat both overt CNS leukemia and the therapy used for the prevention of CNS leukemia. Similarly, the criterion used to define the presence of CNS leukemia differs among the groups. The majority of cooperative groups classify CNS findings in a similar manner, specifically CNS1 status is less than 5 white blood cells in the cerebrospinal fluid (CSF) with no blasts present, CNS2 status is less than 5 white blood cells in the CSF with the presence of blasts, and CNS3 status is 5 or more white blood cells in the CSF with the presence of blasts (all in an atraumatic tap). This manuscript will examine both the definition and therapy of CNS leukemia in pediatric AML cooperative group trials as well as the incidence of CNS relapse in these trials, with recommendations for therapy based on these studies.

In North America, the majority of clinicians treat AML according to the current Children's Oncology Group (COG) phase III clinical trial. In the recently opened phase III trial, COG AAML 1031, patients are treated prophylactically with intrathecal cytarabine at the beginning of each cycle of chemotherapy [1]. Patients are defined as having CNS disease if they meet the following criteria: 1) Any number of blasts in an atraumatic ( $<100 \mathrm{RBCs})$ lumbar puncture; 2) Blasts in a traumatic lumbar puncture in which the WBC/RBC ratio in the CSF is twice that in the peripheral blood; 3) Clinical signs or symptoms of CNS leukemia; or 4) Radiographic evidence of an intracranial, intradural mass consistent with a granulocytic sarcoma. These patients are treated with additional twice weekly intrathecal chemotherapy until their CSF is clear and then 2 additional doses of intrathecal chemotherapy are given. CNS irradiation is not recommended for these patients. The results of this study, and its predecessor, AAML0531, have not yet been published, and so the incidence of CNS relapse is not available. Prior to adopting the Medical Research Council (MRC) backbone of therapy, Children's Cancer Group (CCG) trials treated patients with CNS leukemia only if they had CNS3 disease [2, 3]. Patients with no CNS disease at diagnosis received intrathecal cytarabine at the start of each chemotherapy cycle. Patients with CNS3 status received additional twice-weekly intrathecal cytarabine for a total of 6 doses, and if this failed to clear the leukemia cells they then received twice weekly triple intrathecal therapy for a total of 6 doses. Radiation therapy was supposed to be given to patients who had CNS leukemia that did not clear after 6 doses of intrathecal chemotherapy (dose 2400 cGy). The incidence of an isolated CNS relapse in the patients treated on the previous CCG studies was 1\% in the CNS 1 patients, $4 \%$ in the CNS2 patients and 9\% in the CNS3 patients [4]. In previous Pediatric Oncology Group (POG) AML protocols, CNS disease was diagnosed in patients who had CNS3 status [5]. Patients without CNS disease at diagnosis were treated with 
intrathecal cytarabine at the beginning of each course of chemotherapy. Patients with CNS3 status at diagnosis received two additional doses of intrathecal cytarabine during induction therapy. Low dose cranial irradiation (600 cGy) was permitted for patients with CNS leukostasis. The incidence of CNS relapse in these patients was 7-21\%. The research group at St Jude hospital also recently completed a trial in pediatric AML therapy, St Jude AML97 [6]. In this protocol, patients without CNS disease received four monthly doses of intrathecal cytarabine, hydrocortisone and methotrexate starting on day 15 of therapy. Those patients who had CNS disease received weekly doses of the same intrathecal therapy until the CSF was clear of leukemia cells with a minimum of 4 weekly doses to be given. They then received four monthly doses of the same intrathecal therapy. They classified patients as being CNS positive if they had CNS2 or CNS3 status at diagnosis. In this study they did not have any patients with an isolated CNS relapse.

In the recently completed MRC12 study, children were defined as having CNS leukemia if they had CNS3 status [7]. The CNS directed therapy for patients without CNS disease consisted of triple intrathecal chemotherapy (cytarabine, hydrocortisone and methotrexate) after each of the first three courses of chemotherapy. Children with CNS disease at diagnosis received two courses of weekly triple intrathecal chemotherapy until the CSF was clear plus two additional courses for a minimum of six courses. They then received monthly intrathecal therapy and if they were over the age of 2 years they received cranial irradiation (2400 cGy) at the end of therapy, if they did not receive total body irradiation for transplant conditioning. On this study there was a 7\% incidence of CNS relapse.

The previous AML-BFM studies used cranial irradiation as CNS directed therapy in pediatric AML. This group defines CNS involvement with leukemia as the presence of more than 10 white cells in the CSF with the presence of blasts [8]. The recently completed AML-BFM2004 study examined reducing the dose of cranial irradiation from 1800cGy to 1200cGy [9]. In this study patients received intrathecal chemotherapy at the beginning of each course of therapy as well as during the maintenance phase of therapy during the cranial irradiation given at the end of the therapy. This consisted of monthly intrathecal cytarabine therapy (given 11 times for standard risk patients and 12 times for other patients). The incidence of CNS relapse was $0.4 \%$ in the 1200 cGy group and $2.2 \%$ in the 1800 cGy group [9].

In the recently completed Nordic Society for Pediatric Hematology and Oncology (NOPHO) AML 2004 protocol, CNS involvement with leukemia was defined as children with CNS3 status at diagnosis [10]. In this study, children with CNS involvement received twice weekly intrathecal cytarabine until 1 week after blast clearance and on subsequent courses of chemotherapy received intrathecal methotrexate at the beginning of each course. Children without CNS disease received intrathecal methotrexate at the beginning of each course of chemotherapy. The incidence of CNS relapse on this trial is not published.

The Japanese Childhood AML Cooperative Study Group recently published the results of their AML99 clinical trial [11]. In this study, children were classified with CNS leukemia if they had CNS3 status [12]. This trial used triple intrathecal chemotherapy at the beginning of each course of therapy to and no prophylactic cranial irradiation was used. The incidence of CNS relapse in this study was $1.3 \%$ [11].

The Associazione Italiana di Ematologia e Oncologia Pediatrica (AIEOP) group published a review of their recent protocols [13]. In their studies, CNS prophylaxis consisted of intrathecal cytarabine on the first day of each cycle of chemotherapy. They found an incidence of CNS relapse of 3-5\% on protocols AIEOP LAM 82, AIEOP LAM 87, AIEOP LAM 87M, and AIEOP LAM 92.

Within the French cooperative group, Leucemie Aigue Myeloblastique Enfant (LAME), a recent review of their last 3 trials was published [14]. They administered CNS prophylaxis with intrathecal cytarabine and intrathecal cytarabine/methotrexate/hydrocortisone to all patients with M4 or M5 subtype or patients who had a presenting white cell count of $50 \times 10^{9} / \mathrm{L}$. Patients who had CNS leukemia at presentation received three additional intrathecal chemotherapy doses as well as 2400 cGy of cranial irradiation. The CNS relapse rate was 4\% on LAME 89/91 [15]. 
The Dutch also have completed several cooperative group AML studies. A review of their last 3 studies was recently published [16]. Their studies AML-82, AML-87, and AML-92/94 all differed in their CNS prophylaxis and treatment. In AML-82 no prophylactic intrathecal cytarabine was given and neither was prophylactic cranial irradiation given. In AML-87 all patients received prophylactic intrathecal cytarabine for a total of 5 doses and children with an initial presenting white blood cell count over $70 \times 10^{9} / \mathrm{L}$ received cranial irradiation at a dose from 1200-1800 cGy depending on their age. In AML-92/94 CNS prophylaxis consisted of five doses of intrathecal cytarabine and no cranial irradiation was given. The incidence of CNS relapse was 6\% on AML-82 and AML-87 and was 4\% on AML-92/94.

Table 1. Summary of CNS Disease Definition, Therapy and Relapse Rate

\begin{tabular}{|c|c|c|c|c|}
\hline Study & $\begin{array}{l}\text { Definition of CNS } \\
\text { disease }\end{array}$ & CNS prophylactic therapy & Treatment of CNS disease & CNS Relapse Incidence \\
\hline CCG 2891/2961 & CNS3 & IT cytarabine each course & Twice weekly triple IT \pm XRT & $\begin{array}{l}1 \% \text { CNS1, } 4 \% \text { CNS2, } \\
9 \% \text { CNS3 }\end{array}$ \\
\hline POG & CNS3 & IT cytarabine each course & 2 additional IT cytarabine & $7-21 \%$ \\
\hline St Jude AML97 & CNS2 or CNS3 & Monthly triple IT & Weekly triple IT then monthly & $0 \%$ \\
\hline MRC12 & & Triple IT each course & $\begin{array}{l}\text { Weekly triple IT then each } \\
\text { course + XRT }\end{array}$ & $7 \%$ \\
\hline AML-BFM2004 & $\begin{array}{l}>10 \text { wbc with blasts } \\
\text { in CSF }\end{array}$ & $\begin{array}{l}\text { IT cytarabine each course and } \\
\text { monthly at end therapy, + XRT }\end{array}$ & & $0.4-2.2 \%$ \\
\hline NOPHO-AML 2004 & CNS3 & IT MTX each course & $\begin{array}{l}\text { Twice weekly MTX until clear } \\
+2 \text { then monthly }\end{array}$ & \\
\hline Japanese AML99 & CNS3 & Triple IT each course & & $1.3 \%$ \\
\hline AIEOP 82-92 & & IT cytarabine each course & & $3-5 \%$ \\
\hline LAME 89/91 & & $\begin{array}{l}\text { IT cytarabine each course + IT } \\
\text { Triple if M4/M5/high wbc }\end{array}$ & Three additional IT + XRT & $4 \%$ \\
\hline Dutch AML-82 & & none & & $6 \%$ \\
\hline Dutch AML-87 & & $\begin{array}{l}\text { IT cytarabine each course +XRT } \\
\text { if high wbc }\end{array}$ & & $6 \%$ \\
\hline Dutch AML-92/94 & & IT cytarabine each course & & $4 \%$ \\
\hline
\end{tabular}

Overall, CNS prophylaxis in AML is treated in the majority of protocols with intrathecal therapy (either cytarabine alone or cytarabine with hydrocortisone and methotrexate) (Table 1). With this therapy, the incidence of CNS relapse is quite low. As most patients are undergoing bone marrow examination at the beginning of each course of therapy, it makes good clinical sense to give the intrathecal therapy at this time. Thus, the recommendation of this review is to use intrathecal cytarabine at the beginning of each course of therapy (apart from high dose cytarabine or Capizzi chemotherapy). If all protocols used this approach, it would allow the effect of systemic chemotherapy on CNS relapse to be examined. In terms of treatment of CNS disease, additional intrathecal chemotherapy until the CSF is cleared plus two further, has been shown to be effective therapy and is recommended. The use of cranial irradiation for CNS disease has not shown to have a benefit in terms of survival, and imparts many long term toxicities such as neurocognitive deficits and endocrine deficiencies [17, 18]. Thus it is not recommended for routine use. Finally, the definition of CNS disease needs to be standardized among cooperative groups. We have previously shown that CNS2 patients have equal outcomes to CNS1 patients based on CCG AML protocols [4]. As well, the majority of cooperative groups use the CNS3 definition, or $>5$ white blood cells in the CSF with blasts present, to define CNS disease. It is thus proposed that this definition be used for all pediatric AML trials, again allowing comparison of the effect of systemic chemotherapy on the treatment of CNS disease. If these standard definitions and therapies are adopted across cooperative groups, then the ability to test novel therapies and the effects of systemic therapies will be more easily studied. 


\section{References}

[1] Children’s Oncology Group. www.childrensoncologygroup.org (6 October 2011, date last accessed).

[2] Lange BJ, Smith FO, Feusner J, Barnard DR, Dinndorf P, Feig S, et al. Outcomes in CCG-2961, a children's oncology group phase 3 trial for untreated pediatric acute myeloid leukemia: a report from the children's oncology group. Blood 2008;111:1044-53. PMid: 18000167. http://dx.doi.org/10.1182/blood-2007-04-084293

[3] Woods WG, Neudorf S, Gold S, Sanders J, Buckley JD, Barnard DR, et al. A comparison of allogeneic bone marrow transplantation, autologous bone marrow transplantation, and aggressive chemotherapy in children with acute myeloid leukemia in remission. Blood 2001;97:56-62. PMid: 11133742. http://dx.doi.org/10.1182/blood.V97.1.56

[4] Johnston DL, Alonzo TA, Gerbing RB, Lange BJ, Woods WG. The Presence of Central Nervous System Disease at Diagnosis in Pediatric Acute Myeloid Leukemia Does Not Affect Survival: A Children’s Oncology Group Study. Pediatr Blood Cancer 2010;55:414-20. http://dx.doi.org/10.1002/pbc.22511

[5] Ravindranath Y, Chang M, Steuber CP, Becton D, Dahl G, Civin C, et al. Pediatric Oncology Group (POG) Studies of acute myeloid leukemia (AML): a review of four consecutive childhood AML trials conducted between 1981 and 2000. Leukemia 2005;19:2101-16. PMid: 16136167. http://dx.doi.org/10.1038/sj.leu.2403927

[6] Rubnitz JE, Crews JE, Pounds S, Yang S, Campana D, Gandhi VV, et al. Combination of cladribine and cytarabine is effective for childhood acute myeloid leukemia: results of the St Jude AML97 trial. Leukemia 2009;23:1410-16. PMid: 19242495. http://dx.doi.org/10.1038/leu.2009.30

[7] Gibson BE, Webb DK, Howman AJ, De Graaf SS, Harrison CK, Wheatley K. Results of a randomized trial in children with Acute Myeloid Leukaemia: Medical Research Council AML12 trial. Br J Haematol 2011 Sep 9 [epub ahead of print].

[8] Creutzig U, Ritter J, Zimmermann M, Schellong G. Does Cranial Irradiation Reduce the Risk for Bone Marrow Relapse in Acute Myelogenous Leukemia? Unexpected Results of the Childhood Acute Myelogenous Leukemia Study BFM-87. J Clin Oncol 1993;11:279-86. PMid: 8426205.

[9] Cretuzig U, Zimmermann M, Bourquin JP, Dworzak MN, Fleischhack G, von Neuhoff C, et al. CNS Irradiation in Pediatric Acute Myleoid Leukemia: Equal Results by 12 or 18 Gy in Studies AML-BFM98 and 2004. Pediatr Blood Cancer 2011;57:986-92. http://dx.doi.org/10.1002/pbc.22955

[10] Abrahamsson J, Forestier E, Heldrup J, Jahnukainen K, Jonsson O, Lausen B, et al. Response-Guided Induction Therapy in Pediatric Acute Myeloid Leukemia With Excellent Remission Rate. J Clin Oncol 2011;29:310-15. PMid: 21149663. http://dx.doi.org/10.1200/JCO.2010.30.6829

[11] Tsukimoto I, Tawa A, HoribeK, Tabuchi K, Kigasawa H, Tsuchida M, et al. Risk-Stratified Therapy and the Intensive Use of Cytarabine Improves the Outcome in Childhood Acute Myeloid Leukemia: The AML99 Trial From the Japanese Childhood AML Cooperative Study Group. J Clin Oncol 2009;27:4007-13. PMid: 19620491. http://dx.doi.org/10.1200/JCO.2008.18.7948

[12] Kobayashi R, Tawa A, Hanada R, Horibe K, Tsuchida M, Tsukimoto I. Extramedullary Infiltration at Diagnosis and Prognosis in Children With Acute Myelogenous Leukemia. Pediatr Blood Cancer 2007;48:393-98.

http://dx.doi.org/10.1002/pbc.20824 
[13] Pession A, Rondelli R, Basso G, Rizzari C, Testi AM, Fagioli F. Treatment and long-term results in children with acute myeloid leukaemia treated according to the AIEOP AML protocols. Leukemia 2005;19:2043-53.

PMid: 16107897. http://dx.doi.org/10.1038/sj.leu.2403869

[14] Perel Y, Auvrignon A, Leblanc T, Michel G, Reguerre Y, Vannier JP. Treatment of childhood acute myeloblastic leukemia: dose intensification improves outcome and maintenance therapy is of no benefit - multicenter studies of the French LAME (Leucemie Aigue Myeloblastique Enfant) Cooperative Group. Leukemia 2005;19:2082-89.

PMid: 16121218. http://dx.doi.org/10.1038/sj.leu.2403867

[15] Aladjidi N, Auvrignon A, Leblanc T, Perel Y, Be’nard A, Bordigoni P. Outcome in Children With Relapsed Acute Myeloid Leukemia After Initial Treatment With the French Leucemie Aique Myeloıde Enfant (LAME) 89/91 Protocol of the French Society of Pediatric Hematology and Immunology. J Clin Oncol 2003;21:4377-85. PMid: 14645428. http://dx.doi.org/10.1200/JCO.2003.11.066

[16] Kardos G, Zwaan CM, Kaspers GJL, de-Graaf SSN, de Bont ESJM, Postma A. Treatment strategy and results in children treated on three Dutch Childhood Oncology Group acute myeloid leukemia trials. Leukemia 2005;19:2063-71. PMid: 16107896. http://dx.doi.org/10.1038/sj.leu.2403873

[17]Edelstein K, D'agostino N, Bernstein LJ, Nathan PC, Greenberg ML, Hodgson DC, et al. Long-term neurocognitive outcomes in young adult survivors of childhood acute lymphoblastic leukemia. J Pediatr Hematol Oncol 2011;33:450-58. PMid: 21646917. http://dx.doi.org/10.1097/MPH.0b013e31820d86f2

[18] Lancashire ER, Frobisher C, Reulen RC, Winter DL, Glaser A, Hawkins MM. Educational attainment among adult survivors of childhood cancer in Great Britain: a population-based cohort study. J Natl Cancer Inst 2010;102:254-70. PMid: 20107164. http://dx.doi.org/10.1093/jnci/djp498 